\title{
HER2-Positive Breast Cancer Immunotherapy: A Focus on Vaccine Development
}

\author{
Atefeh Arab ${ }^{1} \cdot$ Rezvan Yazdian-Robati ${ }^{2} \cdot$ Javad Behravan ${ }^{3,4,5}$ \\ Received: 27 June 2019 / Accepted: 16 December 2019 / Published online: 9 January 2020 \\ (c) L. Hirszfeld Institute of Immunology and Experimental Therapy, Wroclaw, Poland 2020
}

\begin{abstract}
Clinical progress in the field of HER2-positive breast cancer therapy has been dramatically improved by understanding of the immune regulatory mechanisms of tumor microenvironment. Passive immunotherapy utilizing recombinant monoclonal antibodies (mAbs), particularly trastuzumab and pertuzumab has proved to be an effective strategy in HER2-positive breast cancer treatment. However, resistance to $\mathrm{mAb}$ therapy and relapse of disease are still considered important challenges in clinical practice. There are increasing reports on the induction of cellular and humoral immune responses in HER2-positive breast cancer patients. More recently, increasing efforts are focused on using HER2-derived peptide vaccines for active immunotherapy. Here, we discuss the development of various HER2-derived vaccines tested in animal models and human clinical trials. Different formulations and strategies to improve immunogenicity of the antigens in animal studies are also discussed. Furthermore, other immunotherapeutic approaches to HER2 breast cancer including, CTLA-4 inhibitors, immune checkpoint inhibitors, anti PD-1/PD-L1 antibodies are presented.
\end{abstract}

Keywords Breast cancer $\cdot$ HER2 $\cdot$ Immunotherapy $\cdot$ Vaccine

\section{Introduction}

Several therapeutic approaches have been established for treating breast cancer including radiotherapy, surgery, hormone therapy, chemotherapy, and immunotherapy. Cancer immunotherapy includes several modalities including but not limited to cancer vaccines, monoclonal antibodies (mAbs), adaptive cell therapy, chimeric antigen receptor T cell therapy (Miliotou and Papadopoulou 2018) and in oncolytic virus therapy, all aiming to attack and kill tumor cells (McCarthy 2006). It has been documented that the

Javad Behravan

behravanj@mums.ac.ir; javad.behravan@uwaterloo.ca

1 Pharmaceutical Sciences Research Center, Ardabil University of Medical Sciences, Ardabil, Iran

2 Molecular and Cell Biology Research Center, Faculty of Medicine, Mazandaran University of Medical Sciences, Sari, Iran

3 Biotechnology Research Center, Mashhad University of Medical Sciences, Mashhad, Iran

4 School of Pharmacy, University of Waterloo, Waterloo, ON, Canada

5 Theraphage Inc., Kitchener, ON, Canada most immunogenic breast cancer subtypes are the human epidermal growth factor receptor 2 (HER2)-positive and triple-negative breast cancer (TNBC). Thus, activating the patient's own immune system to abolish the tumor cells is a promising and a relatively new therapeutic approach. The advantage of active immunotherapy is the development protective effect against tumor tissue, resetting the immune system to an anti-tumor surveillance status (Williams et al. 2017). Active immunotherapy via vaccination is based on the ability of immune system to differentiate between self-antigens that are expressed normally on the surface of cells and those overexpressed abnormally on tumor cells. Tumor-associated antigens (TAA) like HER2 are identified as appropriate sources for peptide vaccination in breast cancer (Marmé 2016). Using immune checkpoint inhibitors is another very successful immunotherapy approach tested in a variety of cancers. mAbs targeting the cytotoxic $\mathrm{T}$ lymphocyte-associated antigen (CTLA)-4, programmed cell death (PD)-1 and programmed death-ligand 1 (PD-L1) have impressive outcomes in several malignancies and have been investigated as single agents or as combinations with chemotherapy medications in breast cancer (Schmid et al. 2018; Solinas et al. 2017). 


\section{Tumor Microenvironment}

Immune cells as major components of the tumor microenvironment (TME) play crucial role in the recognition/ prevention, early eradication and progression of cancer. Immune system elements such as dendritic cells (DCs), macrophages, natural killer (NK) cells and adaptive immune cells penetrate in TME and their presence in TME signals an anti-tumor immune response (Tan et al. 2018).

The theory of "immunoediting" which includes elimination, equilibrium and escape phases describes the role of immune system in the progression and development of cancer (Schreiber et al. 2011). In the "elimination phase", immune cells identify and eradicate cancer cells to prevent tumor growth. In the second stage "equilibrium phase", scarce cancerous cells that evade the elimination phase remain dormant, while immune cells prevent tumor cell outgrowth. Cancer cells that avoid immune recognition and elimination step, enter the "escape stage" and proceed to proliferate aggressively (Ayoub et al. 2019). Activation of $\mathrm{CD}^{+}$cytotoxic $\mathrm{T}$ lymphocytes (CTLs) is the major part of anticancer immunity that exert anti-tumor activity by secreting tumor necrosis factor (TNF)- $\alpha$ and interferon (IFN)- $\gamma$ along other cytotoxins ( $\mathrm{Su}$ et al. 2016; Sugie and Toi 2017). The number of CTLs in TME and their capacity to distinguish TAA have great influence in inhibiting tumor growth and development of malignancy (De La Cruz et al. 2016; Zhou et al. 2016). Tumor cells can evade immune system by lowering the expression or by modification of surface antigens, down-regulation of major histocompatibility complex (MHC) class I proteins, $\mathrm{T}$ cell receptor signaling defect and down-regulating of the expression of co-stimulatory molecules (Tan et al. 2018). Other mechanisms to escape immune detection are blocking regulatory pathways activation, development of immunosuppressive TME via regulatory T cells (Tregs), increasing the myeloid-derived suppressor cells, production of tumor growth factor $\beta$ and interleukin (IL)-10 cells (Ayoub et al. 2019). Tumor infiltrating lymphocytes (TILs) consist of T and B lymphocytes, NK cells, DCs and macrophages surrounding cancer cells (Chin et al. 1992). Identification of TILs in TME can predict the immunogenic nature of cancer and response to therapy and improved prognosis. The quantity of TILs and the phenotype of infiltrated cells determine the clinical outcome of the therapy. Presence of CD8 ${ }^{+}$CTLs are essential for tumor cell destruction and is related to a lower rate of fatality in estrogen receptor (ER)negative, ER-positive and HER2-positive tumors. CD4 ${ }^{+}$ T-helper (Th) cells are positively correlated with forkhead box P3 (Foxp3) CD4 ${ }^{+}$Treg cells and have negative effects on the CTL function. $\mathrm{CD} 4^{+} \mathrm{T}$ cells have distinct functions during tumor development. Th1 cells are the predominant subset of $\mathrm{CD}^{+} \mathrm{T}$ cells in the early stage of tumor and are important for immunosurveillance. However, in the advanced stage of cancer, Foxp $3^{+}$Treg and Th17 cells become the dominant subsets of $\mathrm{CD} 4^{+}$TILs which may contribute in promoting tumor growth (Huang et al. 2015).

It has been found that $\mathrm{CD} 4^{+} \mathrm{T}$ cells are associated with larger tumor sizes and higher tumor stages, positive lymph node status and expression of HER2 in advanced breast cancer patients (Ayoub et al. 2019; Tan et al. 2018). Strong correlation between the expression of lymphocyte genes and reduction of cancer recurrence rates has been observed in HER2-positive breast cancer (Alexe et al. 2007). As reported in a study of 387 cases of HER2-positive breast cancer patients, there was $3 \%$ relative reduction in the risk of recurrence for each one percent increase in TILs (Salgado et al. 2015).

\section{HER2-positive Breast Cancer Immunotherapy}

HER2, known as ErbB-2 (Erythroblastosis homolog B2) CD340 or p185, is a $185 \mathrm{kD}$ oncoprotein that is encoded by the ErbB2 gene. It consists of three domains including an intracellular domain with tyrosine kinase property, a transmembrane domain and extra cellular domain (Ladjemi et al. 2010; Slichenmyer and Fry 2001). Higher expression of HER2 in breast cancer is associated with an increase in aggressiveness in clinical behavior, more invasiveness, recurrence and in the absence of immunotherapeutic options, poor chemotherapeutic outcome (Behravan et al. 2018). A growing body of evidence clearly suggest that the interaction between tumor and immune cells in HER2-positive tumors is a critical step in host cellular immunity (Curigliano et al. 2016). The ability of HER 2 in breast cancer cells to interact with any existing receptor tyrosine kinase binding partner leads to $\mathrm{T}$ cells and antibody responses induction against the HER 2 protein. Approximately $20-30 \%$ of all invasive breast cancer cases are classified in the subclass of HER2-positive tumors (Cui et al. 2018).Endogenous HER2 specific antibodies and $\mathrm{T}$ cell activities against HER2 are observed in breast cancer patients overexpressing HER2, suggesting that stimulation of anti-HER 2 immune response could be exploited to eliminate cancerous cells in HER2-positive breast cancer (De La Cruz et al. 2016; Disis et al. 2004). Moreover, overexpression of HER2 on the surface of tumor cells is a major marker for tumor growth and represents a promising target for cancer immunotherapy (Ladjemi et al. 2010).

\section{Targeting of HER2 by Monoclonal Antibodies}

Immunotherapy using $\mathrm{mAbs}$ has been improved as an immune-based therapeutic strategy to directly target HER2 
in breast cancer (De La Cruz et al. 2016). Trastuzumab (Herceptin) as a first humanized mAb directly targets the extracellular domain of HER 2 protein. It has been approved by the Food and Drug Administration (FDA) since 1998 for metastatic HER2 overexpressing breast cancer in combination with chemotherapy. Several clinical trials have demonstrated that a combination of trastuzumab with chemotherapy has prolonged the disease-free survival (DFS) in patients with metastatic HER2/neu-overexpressing breast cancer (Knutson et al. 2016; Slamon et al. 2001). The rational for combination of immunotherapy and chemotherapy is due to their synergistic effects. It was indicated that antibodies potentiate the cytotoxicity effects of chemotherapeutic agents in tumor cell lines overexpressing growth factor receptors (Aboud-Pirak et al. 1988; Pietras et al. 1994; Takahashi et al. 1988). The mechanism of the observed synergistic effects could be the depletion of DNA repair activity by binding of antibodies to the epidermal growth factor receptor extracellular epitopes or to HER2 itself (Arteaga et al. 1994; Pietras et al. 1998). Currently, a new drug named Kadcyla (T-DM1 or ado-trastuzumab emtansine) is approved by the FDA for treating the patients with metastatic breast cancer already treated with taxane and trastuzumab either alone or in combination. T-DM1 is an antibody-drug conjugate that comprises of trastuzumab covalently linked to the cytotoxic agent DM1, a microtubule polymerization inhibitor, to deliver emtansine to the antigen expressing cells. It was reported that T-DM1 was able to reduce the risk of recurrence or prevent death in HER2-positive breast cancer patients harboring remaining residual tumor after neoadjuvant therapy and surgery (Arteaga et al. 1994). Pertuzumab (Perjeta) is another humanized $\mathrm{mAb}$ that blocks HER2 signaling and improves the survival rates when administrated with trastuzumab and docetaxel in metastatic breast cancer (Leung et al. 2018; Swain et al. 2015). Pertuzumab specifically binds to HER 2 extracellular subdomain II and blocks HER 2 dimerization (Franklin et al. 2004). The most probable mechanism of synergistic effects of trastuzumab and pertuzumab is their different modes of function in targeting HER2-positive breast cancer (Nami et al. 2018).

Results of a CLEOPATRA (Clinical Evaluation of Pertuzumab and Trastuzumab) study after 51 months follow up indicated that adding of pertuzumab to docetaxel and trastuzumab therapy led to the improvement of overall survival. Therefore, this therapeutic regimen was established as the first line treatment for HER2-positive metastatic breast cancer (Swain et al. 2015). Despite the high efficiency of these anti-HER 2 antibodies, the problem of drug resistance and eradication of the minimal residual disease should be considered (Mosaffa et al. 2012; Elahian et al. 2009; Sabahi et al. 2010). Therefore, new treatment strategies to improve disease therapy outcome are needed (Ladjemi et al. 2010).

\section{Vaccines for HER2-positive Breast Cancer}

Active cancer immunotherapy has received an extensive attention in recent years. A cancer vaccine elicits the patient's immune system to produce an anti-tumor response that would produce or activate a wide range of immune regulators such as CTLs, antibodies and Th cells. The vaccination strategy has some advantages over mAbs mediated immunotherapy including fewer administrations, cost effectiveness, and generation of immunological memory. The immune memory advantage helps the immune system to recognize and respond to the antigens in future exposures and protect against the relapsing tumor (Ayoub et al. 2019; Williams et al. 2017). Active immunotherapy with vaccines is based on the induction of a tumor-destructive environment using type I immunity (Th1) toward cancerous cells distinguished with tumor antigens. Immune responses against HER2-positive breast cancer are induced by both CTLs and CD4 ${ }^{+}$T cells (Costa et al. 2017). CTLs as key elements in anticancer immunity are activated by the anticancer vaccines and secrete IFN- $\gamma$, TNF- $\alpha$ and several other cytokines (Jinushi 2015). CD8 ${ }^{+}$cells are capable to recognize HER2 peptides presented by MCH class I molecules, induce cell cycle arrest and apoptosis, and kill the tumor cells by producing IFN- $\gamma$ (Mukai et al. 2002). CD4 ${ }^{+} \mathrm{T}$ cells also play an important role in breast cancer therapy and are associated with stronger anti-HER2 immunity response (Datta et al. 2016). Different strategies including specific tumor antigen-derived peptides, proteins, DNA, RNA, whole tumor cells and DCs can be used for breast cancer vaccine development (Doyle et al. 2018; Kim et al. 2014; Norell et al. 2010; Tomasicchio et al. 2019).

\section{HER2-derived Peptide Vaccines}

Immunogenic HER2-derived peptides include peptides from different parts of HER2 molecule consisting E75 (from the extracellular domain), AE37 (intracellular domain), and GP2 (transmembrane domain). E75 (HER2/neu 369-377: KIFGSLAFL) represents an immunodominant CTL epitope with high affinity for human leukocyte antigen HLA-A2 and HLA-A3 molecules (Datta et al. 2015; Kawashima et al. 1998; Patil et al. 2010). It is expressed in about $60-75 \%$ of the population and is capable to stimulate $\mathrm{T}$ cells against HER2 expressing breast cancer cells. The effects of E75 in induction of immune system of patients with overexpressing HER2 cancers has been established in preclinical studies (Fisk et al. 1995; Kuerer et al. 2002; Patil et al. 2010; Pietras et al. 1994; Sotiropoulou et al. 2003). Moreover, the efficacy of E75 has been studied at varying dose schedules in clinical trials (Table 1). The highest and most advanced clinical trials on the HER2-derived peptides are those of E75 peptide (Nelipepimut-S). In a phase I/II trial, 187 women 


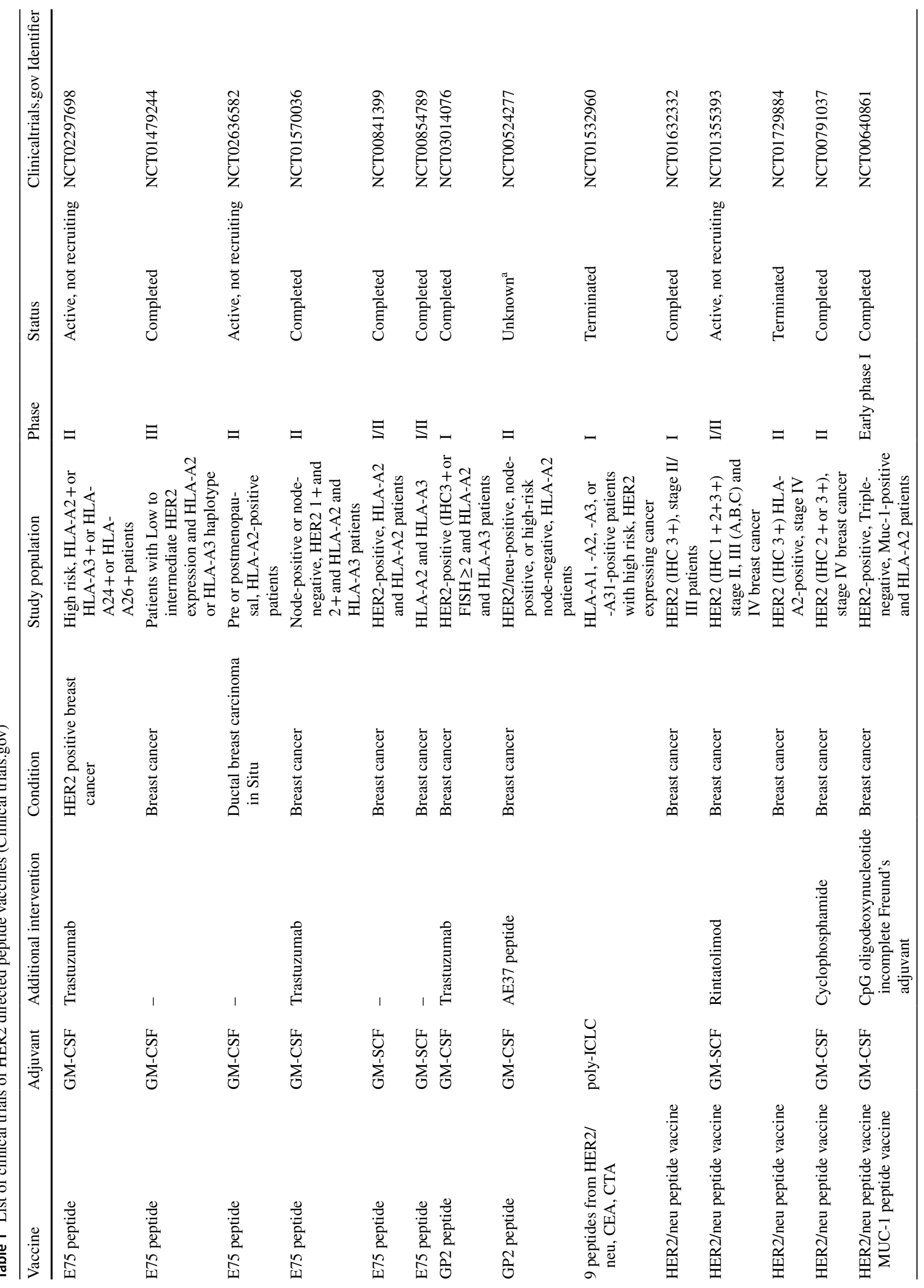


with node-positive and node-negative cancer harboring HER 2 expressing tumors (IHC $1+$ to $3+$ ) were participated. 108 patients with HLA-A2/3 were administered the E75 peptide plus granulocyte-macrophage colony stimulating factor (GM-CSF) and 79 HLA-A2/3 negative patients were selected in the control group. The 5 year DFS was improved in vaccinated patients $(89.7 \%)$ compared to control group) $80.2 \%$; $P=0.08$ ) (Mittendorf et al. 2014).

Based on the observed promising outcome, the clinical efficacy and safety of E75 + GM-CSF (NeuVaxTM, Galena Biopharma, Inc., Portland, OR, USA) vaccine in prevention of breast cancer recurrence has been investigated in a controlled phase III study (PRESENT trial, NCT01479244). In this study, 758 HLA-A2/A3 breast cancer patients with the following criteria: (1) early stage node positive and (2) lowto-intermediate level of HER2 expression after completed standard of therapy, were enrolled. Preclinical data indicated that combining of passive immunotherapy with active immunotherapy might have a synergistic effect. Antibody-dependent cell-mediated cytotoxicity (ADCC) is considered as one of the main mechanisms of action of trastuzumab. Through the ADCC mechanism, trastuzumab-coated tumor antigens are released from tumor cells and taken up by DCs and presented on MHC class I molecules. Therefore, trastuzumab in combination with active immunotherapy, led to the greater expansion of peptide specific CTLs and higher cytotoxicity via enhancement of uptake and cross presentation of HER2 specific epitopes by DCs (Clifton et al. 2016).

Observations from early stages of E75 trial indicated that there was a potential synergistic effect between trastuzumab and E75 vaccine. In a clinical trial study, 12 HER2 (IHC $3+$ ) patients received trastuzumab followed by an E75 vaccine. The patients were observed for 5 years. No cancer recurrences were seen in any of patients after 5 years of follow up (Mittendorf et al. 2012). This was followed by two other studies on the concurrent administration of E75 vaccine and trastuzumab. In the first study, high-risk HER2 breast cancer patients randomized to either traustuzumab plus nelipepimut-S (E75) + GM-CSF vaccine treatment, or only trastuzumab. There were no disease recurrences after 36 months of follow up in patients treated with trastuzumab followed by vaccination with nelipepimut-S(NCT02297698) (Mittendorf et al. 2015). In the second study, patients with low-expression of HER2 (IHC $1+$ or $2+$ ) breast cancer (after completion of standard therapy), were vaccinated with nelipepimut-S + GM-CSF and trastuzumab or trastuzumab + GM-CSF. No significant differences in toxicity especially cardiotoxicity among immunized patients were observed. This trial is ongoing, and the clinical efficacy will be available after completion of the study (NCT01570036) (Clifton et al. 2019). GP2 is another nanopeptide (654-662: IISAVVGIL) derived from the transmembrane domain of the HER2/neu protein. GP2 has been known as a subdominant 
epitope with poor binding affinity to HLA-A2 molecule (Ayoub et al. 2019; Clive et al. 2012; Cui et al. 2018). Initially in various studies, GP2 peptide immunogenicity was investigated, and the peptide GP2 was introduced as a promising antigen for breast cancer vaccine application (Brossart et al. 1998; Mittendorf et al. 2006; Peiper et al. 1997; Yoshino et al. 1994). In a phase I clinical trial, the safety, immunogenicity and the best doses of the GP2 peptide plus GM-CSF were assessed. Patients were lymph node-negative and expressed HER2 based on immune histochemical analysis (IHC 1-3+). All patients received standard therapy and were disease free. HLA-A2 + patients were vaccinated with increasing doses of the GP2 peptide and GM-CSF. The safety of vaccine was demonstrated with minimal local and systematic toxicity including erythema, induration, pruritis, inflammation and fatigue. The trial indicated that the vaccine was able to elicitaGP2 specific immune response in patients (Carmichael et al. 2010). A phase II trial was then conducted to investigate the GP2 vaccine efficacy in preventing recurrence in node-positive and high-risk node-negative HER2 breast cancer patients (IHC 1-3+) (NCT00524277). Disease-free patients with HLA-A2-positive after receiving standard therapy, were divided in two groups including a control group (only received GM-CSF) and a treatment group (received GP2 vaccine + GM-CSF). The 5-year DFS rates in (IHC $3+$ and FISH $1+$ ) patients vaccinated with GP2 was increased compared to the control group. However, the benefits were not statistically significant for the patients $(P=0.08)$. Using intention-to-treat analysis, after 34 months of follow up, the 5 year DFS rate was estimated to be $88 \%$ in the treatment group and $81 \%$ in GM-CSF group $(P=0.43)$ (Mittendorf et al. 2016). In addition, this research reported that a combination therapy of GP2 + GM-SCF vaccine with trastuzumab in HER 2 overexpressing breast cancer patients was safe with limited local or systemic toxicity and without any increase in cardiotoxicity. A list of clinical trials of GP2 vaccines are listed in Table 1.

AE37 is another HER2-derived peptide (Ii-key hybrid of MHC II peptide AE36 (HER2/neu 776-790) is identified to be capable in inducing both $\mathrm{CD} 8^{+}$and $\mathrm{CD} 4^{+}$cells. The presence of Ii-key, a four-amino-acid LRMK, enhances vaccine effectiveness by increasing epitope charging resulting in improved antigen presentation (Gillogly et al. 2004). Fifteen disease-free, node-negative patients received hybrid AE37 and GM-CSF for 6 months on a dose escalation method in a phase I study. AE37 was safe and found to induce HER2 specific immune response both in vivo and in vitro (Benavides et al. 2008). Furthermore, the AE37 peptide vaccine showed potency in the absence of an immunoadjuvant (Holmes et al. 2008). Due to the positive results from phase I trial, a phase II trial (NCT00524277) was conducted to analyze the benefits of AE37 + GM-SCF vaccine in preventing the recurrence rate in node-positive and high-risk node-negative breast cancer patients. The patients were inoculated with AE37 and GM-CSF did not show a significant difference in recurrence rate and 5 year DFS, but data from this study indicates of the benefit of AE37+GM-SCF vaccine in reduction the recurrence rate in TNBC patients which need further clinical investigation (Mittendorf et al. 2014).

\section{Strategies to Improve Immunogenicity of Peptide Vaccines}

Due to poor immunogenicity of single peptide vaccines in inducing suitable immune response and particularly inducing cell-mediated immunity, considerable attention has been devoted to enriching the anti-tumor activity of peptide vaccines by inclusion of different adjuvants and delivery vectors. For this purpose, nano-delivery strategies including liposomal, virus-like particle, polymeric and non-degradable nanoparticle delivery approaches have been considered in recent years. There are potential advantages in using these vaccine delivery vectors over the application of immunologic peptide alone. Liposomes have the potential to help peptide antigen delivery to the lymph nodes and to increase the cellular uptake by DCs resulting in enhancement of peptide immunogenicity (Alving 1991; Krishnamachari et al. 2011; Watson et al. 2012). In addition, liposomes act as immune adjuvants to enhance and prolong the immune response (Nordly et al. 2009). In a study reported by our group, liposomal formulations composed of dioleoylphosphatidylethanolamine (DOPE), distearoylphosphocholine, distearoylphosphoglycerol and cholesterol carrying E75 peptide were developed. Liposomal formulations were used both as delivery vehicles and as immune adjuvants for enhancement of the stimulation of immune response against established rHER2/ neu protein overexpressing tumors in BALB/c mice. The liposomal formulation of E75 peptide was able to evoke specific $\mathrm{CD}^{+}$CTLs response that protected mice against HER 2 tumor challenge in both therapeutic and prophylactic experiments (Arab et al. 2018a). Moreover, and in a similar line of research, we formulated the GP2 peptide in liposomal carriers consisting of dimyristoylphosphatidylcoline, dimyristoylphosphoglycerol, DOPE, cholesterol and monophosphoryl lipid A (as an adjuvant). The GP2 containing nano-liposome improved the immunogenicity of the GP2 peptide in inducing T cell immunity in BALB/c mice model of TUBO xenograft cancer and potentially reduced the tumor development and, prolonged survival time in mice (Razazan et al. 2017). Furthermore, we have reported that encapsulation of the AE37 peptide in nanoliposomes composed of DOTAP ( $N$-[1-(2, 3-Dioleoyloxy) propyl]- $N, N, N$-trimethylammoniummethyl-sulfate), DOPE and cholesterol with CpG (as an adjuvant) elicited both cellular and humoral immunity leading to potential therapeutic and protective effects in BALB/c mice bearing 
HER2 breast cancer (Barati et al. 2017). Phage display is another valuable technique for vaccine discovery which has been exploited by many research groups including our group (Arab et al. 2018b, c, 2019; Frenzel et al. 2016). It has been shown that antigen-presenting cells (APCs) readily take the immunogenic molecules from the displaying phage, process and present them on MHC I and MHC II molecules to induce higher immune responses compared with soluble antigens with no carriers (Prisco and De Berardinis 2012). In addition, there are many other advantages for phage vector application in vaccine delivery that include the phage intrinsic adjuvant activity, higher stability, easy and cost effectiveness of construction and manufacturing, safety profile and the high multivalent phage-display potential. These advantages make phagederived nanoparticles potential candidates for phage-based vaccine delivery systems (Arab et al. 2019).

Our group evaluated the immune response induction by the E75 peptide displayed on phage $\lambda F 7$ (gpD::E75) in TUBO tumor of $\mathrm{BALB} / \mathrm{c}$ mice. Before and after vaccination the animals were challenged in vivo with the TUBO xenograft tumor cells (for therapeutic and prophylactic evaluation of the vaccine). Results of this study indicated that stimulation of E75 specific $\mathrm{CD}^{+} \mathrm{T}$ cells resulted in higher titers of IL-4 and IFN- $\gamma$ in vaccinated mice compared to control ( $\lambda$ F7) and buffer groups (Arab et al. 2018b). In addition, we have shown the anti-tumor activity of GP2 and AE37 peptides displayed on phage $\lambda F 7$ (gpD::GP2 and gpD::AE37) in $\mathrm{BALB} / \mathrm{c}$ mice with the TUBO tumor. The prophylactic and therapeutic activities against TUBO tumor model in mice indicated effective immunogenicity of the designed phage display systems (Barati et al. 2018; Razazan et al. 2019).

The B-subunit of Shiga toxin (STxB) has been also used as a delivery vehicle to optimize the E75 vaccine efficacy by targeting DCs. The STxB-E75 vaccine in combination with GM-CSF and CpG was shown to be more potent than the free E75 peptide or STxB-E75 without adjutants in induction of $\mathrm{E} 75$ specific anti $\mathrm{CD} 8^{+} \mathrm{T}$ cells and inhibited the tumor growth in murine HLA-A-2 expressing low levels of HER2/ neu (Tran et al. 2016). Polyactin A (PAA) is an antibiotic which was obtained from a streptococcus strain and used in China for treatment of various disease caused by immune system dysfunction. PAA as an unprecedented immunological adjuvant was also exploited to improve the immune system in peptide-based cancer vaccines (Bi et al. 2008). Culturing of peripheral blood mononuclear cells (PBMCs) in the presence of PAA, IL- 4 and TNF- $\alpha$ could sensibly induce differentiation and maturation of DCs from PBMCs and resulted in higher expression of CD80, CD83, CD86 and HLA-DR compared to negative control. These DCs were able to stimulate efficacious $\mathrm{T}$ cell responses against E75 peptide in vitro. In an in vivo evaluation of the potential E75 vaccine formulation, C57BL/6-Tg (HLA-A2.1) 1Enge/J transgenic mice were vaccinated with E75 and PAA. This resulted in positive rates of $\mathrm{CD} 4^{+}$and $\mathrm{CD} 8^{+} \mathrm{T}$ lymphocytes and IFN- $\gamma$ in splenocytes (Wang et al. 2018).

\section{Anti-idiotype Based Vaccines}

One of the most troubling obstacles in cancer vaccination is the immunological tolerance, probably due to antigens of self-origin (Nanda and Sercarz 1995). Anti-idiotype (anti-Id) antibodies in cancer immunotherapy, which mimic TAA are used to circumvent the tolerance phenomenon (Lollini et al. 2005). scFv40 and scFv69 are human anti-Id scFv antibodies fragments that were chosen through a phage-display library screening using the anti-HER2 antibody trastuzumab in sera of immunized BALB/c mice (Teulon et al. 2006). Ladjemi et al. (2011) reported the protection effects of anti-trastuzumab anti-Id scFv69 in vaccinated transgenic BALB/c mice from development of HER2-positive breast tumors. This protection effects could be due to anti-HER 2 antibody induction, immune response associated to Th2 cells and reverse HER2 immunological tolerance (Ladjemi et al. 2011).

\section{Vaccines Based on Large Fragments of HER2 Protein}

Although peptide-based vaccines have many advantages in eliciting immune system, but they suffer from many limitations. As discussed above, the majority of peptide vaccines are HLA restricted and epitopes specific for HLA class I that may need Th adjuvant to promote persistence of CTLs response (Knutson et al. 2016). Whole protein vaccines include both HLA class I and II epitopes and also are not HLA restricted (Disis et al. 1999). Animal experiments have shown an induction of immune response after immunization with protein-based vaccines. Vaccination of mice with a complex of extracellular domain (ECD) of human HER2 and anti-human HER2/neu IL-2, IL-12 or GM-CSF fusion protein, inhibited the growth of SK-BR-3 human breast tumor cells significantly and protected mice against the TUBO tumor expressing HER2/neu due to eliciting both antibodies and cellular responses against HER2/neu (Cruz et al. 2003). Twenty-five patients in different stages of HER2-positive breast cancer (II, III, or IV) were vaccinated with HER2 intracellular domain (ICD) protein in combination with GM-CSF once a month for 6 months. Most of the vaccinated patients tolerated and promoted both HER2, ICD specific T cell and humoral responses. After the completion of immunization, more than half of the patients maintained the CTLs immunity for 9-12 months. However, the vaccine dosage did not influence the extent of $\mathrm{T}$ cell and antibody responses. The authors nevertheless observed that using a higher dose of the vaccine was correlated with fasteranti-HER2 immunity in patients (Disis et al. 2004). In another study, Kitano et al. (2006) utilized CHP-HER2 (a 
protein-based vaccine consisting of a truncated HER2 protein, (amino acids 1-146 of HER2) and cholesterylpullulan (CHP). Patients vaccinated subcutaneously with CHP-HER2 received three doses of the vaccine, each dose separated by a 2 week period, followed by a booster injection. The vaccine was well-tolerated with transient skin reactions (grade 1) at the site of injection and specific $\mathrm{CD}^{+}$and/or $\mathrm{CD} 4^{+} \mathrm{T}$ cell responses were developed in patients against the truncated HER2 protein (Kitano et al. 2006). In the second part of this clinical trial, nine patients were immunized with the vaccine alone followed by administration of the adjuvant GM-CSF or OK-432. Other six patients, from the beginning of the vaccination plan treated with CHP-HER2 plus GM-SCF. The authors demonstrated that 146 different HER2 specific antibodies were induced in 14 patients; however, the immune response was detectable earlier in those immunized by CHPHER2 with GM-CSF at the first cycle of vaccination. This indicated that GM-CSF has a role in acceleration of immune response in the patients immunized with CHP-HER2 plus GM-CSF at the onset of the immunization (Kageyama et al. 2008). Another anti-HER2 protein-based vaccine, dHER2, a fusion protein consisting of ECD of HER2 and a portion of HER2 ICD plus the immune- stimulant AS15, was evaluated by Curigliano et al. (2016). Forty subjects with HER2-positive metastatic breast cancer were vaccinated by this group with dHER2. Vaccine was safe and only adverse effects grade $1 / 2$ such as myalgia, back pain, chest pain, and diarrhea were reported. Cellular and antibody immunity to the dHER2 were observed. Twenty-five percent of patients producedanti-HER2 long term immunity (Kroemer et al. 2015). Table 2 represents a list of clinical trials for immunogenicity of HER2 protein-based vaccines.

\section{DNA Based Anti-HER2 Vaccines}

In DNA (genetic) vaccines, the DNA coding the tumor antigen is presented by a plasmid which is injected into the host. The DNA-based vaccine can be used to stimulate antigen specific adoptive and nonspecific innate immunity ( $\mathrm{Li}$ et al. 2012). This strategy is considered as one of the most practical ways for cancer immunotherapy because of its simplicity, safety, stability and cost effectiveness (Yang et al. 2014).

Many vaccine studies have provided evidence for the efficacy of HER2 DNA vaccine in the prevention of tumor development in HER2 transgenic mice and transplantable tumor models (Chen et al. 1998; Jacob et al. 2006; Marchini et al. 2013; Rovero et al. 2000; Yang et al. 2014). A DNA sequence coding for full extracellular domain or four extracellular subdomains of human HER2/neu was cloned into pCMV6-Neo vector. An anti-HER2 antibody was raised in the serum of BALB/c mice vaccinated with full extracellular domain of HER2, whereas none of extracellular subdomains induced detectable levels of anti-HER2 antibody
(Sadri-Ardalani et al. 2016). In a similar work, it was reported that a DNA vaccine, $\mathrm{p} 185$ with plasmid coding both the transmembrane domain and the extracellular domain of rat-p185 could protect transgenic BALB/c mice against TUBO cancer cells (Rovero et al. 2000). DNA sequences corresponding to the ligands and immune- adjuvants have been fused to improve the immunogenicity of tumor antigens. For instance, a research group fused the human heat shock protein, hsp70 to the extracellular domain of rat HER2/neu (NeuEDhsp70). Hsp70 could promote DC activation resulting in immune-enhancing cytokine production and priming antigen specific T cells (Todryk et al. 2003). The NeuEDhsp70 DNA vaccine promoted Neu-specific antibody and cellular immune responses in vivo and significantly reduced the metastasis with enhancing the survival rate in a spontaneous metastatic breast tumor model (Kim et al. 2005). Similarly, Pakravan et al. (2010) have reported on a DNA vaccine made of GP96+HER2/neu. A reduction in $\mathrm{CD} 4^{+} \mathrm{CD} 25^{+} \mathrm{Foxp} 3^{+}$at the tumor site and enhancement of IFN- $\gamma / \mathrm{IL}-4$ levels were observed in BALB/c mice harboring TUBO tumor after vaccination with GP96 + HER2/neu DNA vaccine (Pakravan et al. 2010). Chemokines such as CCR7 ligands Epstein-Barr-virus-induced-molecule-1-ligandchemokine (ELC/CCL19) and secondary lymphoid-tissue chemokine (SLC/CCL21) have great roles in regulating the innate and adoptive immune responses and have been investigated in two different studies (Förster et al. 2008; Stewart and Smyth 2009; Viola et al. 2006). In one study, NguyenHoai et al. (2012a) used CCL21 as an attractive adjuvant to boost the immunogenicity of HER2/neu DNA-based vaccine in a BALB/c mice model. Results of this study demonstrated that co-expression of CCL21 and HER2/neu induced immune responses via TH1 cells and improved the protective effects of the HER2/neu DNA vaccine. CCL21 also showed a synergistic activity with GM-CSF in increasing the tumor protective effects in mice vaccinated with HER2/ neu DNA vaccine (Nguyen-Hoai et al. 2012a). In another study, the adjuvant activity of CCL19 in HER2/neu DNA vaccine was evaluated in BALB/c mice harboring HER2 cancer. Co-administration of pDNA (CCL19) with HER2/ neu DNA vaccine improved the protective efficacy of the vaccine (Nguyen-Hoai et al. 2012b). In a preclinical study, a polypeptide DNA vaccine was designed which consisted of the full length of HER2 protein and mammaglobin-1. Poly Th epitopes were added to the construct to obtain an optimal induction of immune system by $\mathrm{CD} 8^{+}$and $\mathrm{CD} 4^{+}$ $\mathrm{T}$ cells. The expression and effectiveness of the vaccine was tested in human DCs. The level of $\mathrm{CD} 86^{+}$and $\mathrm{CD} 83^{+}$ cells increased significantly on transfected DCs which could establish interactions with T cells on their surface. Furthermore, the production of IL-6 was increased with DC maturation. This demonstrated the ability of the test vaccine to induce immune response (Nazarkina et al. 2016). The first 


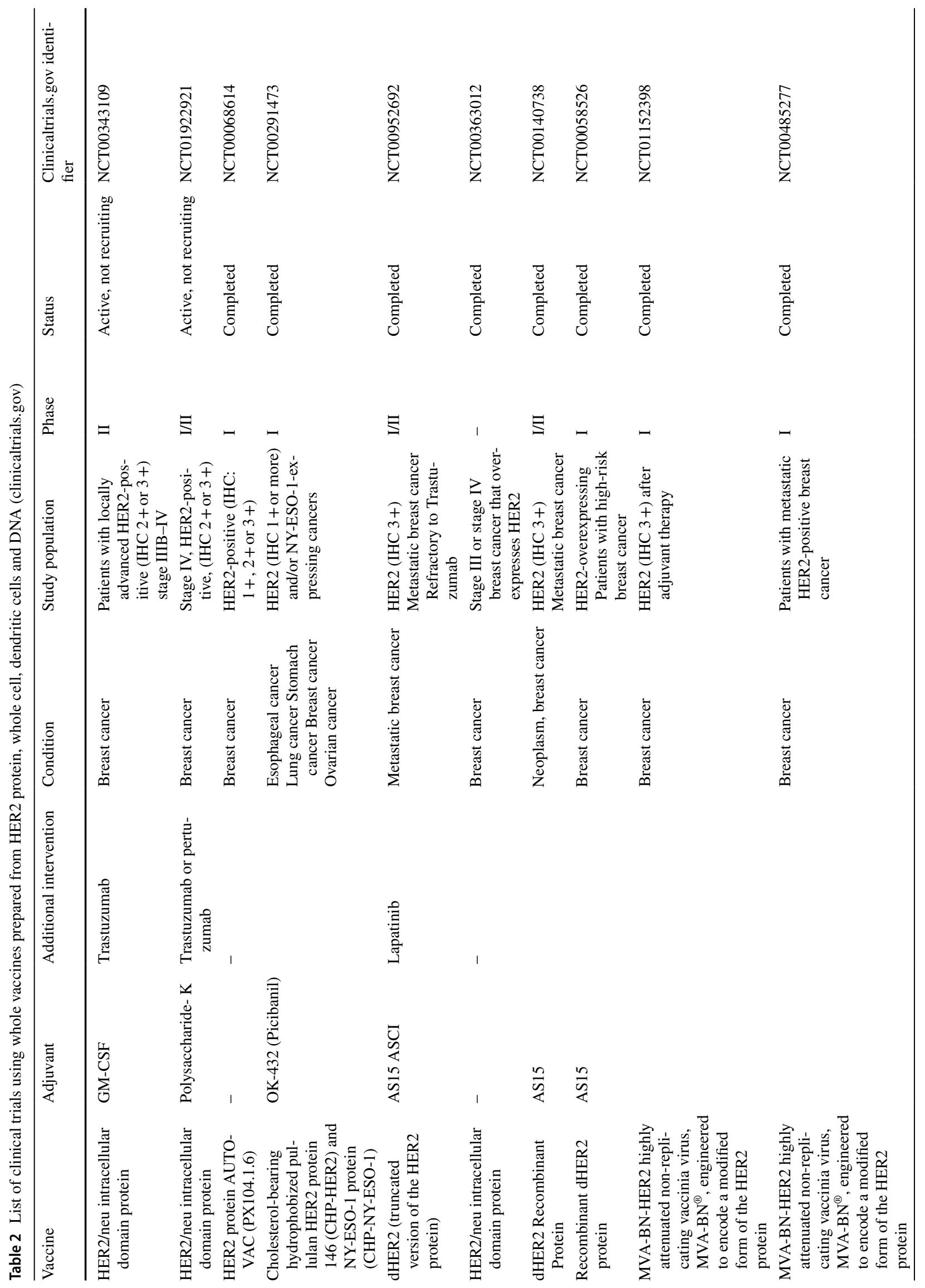




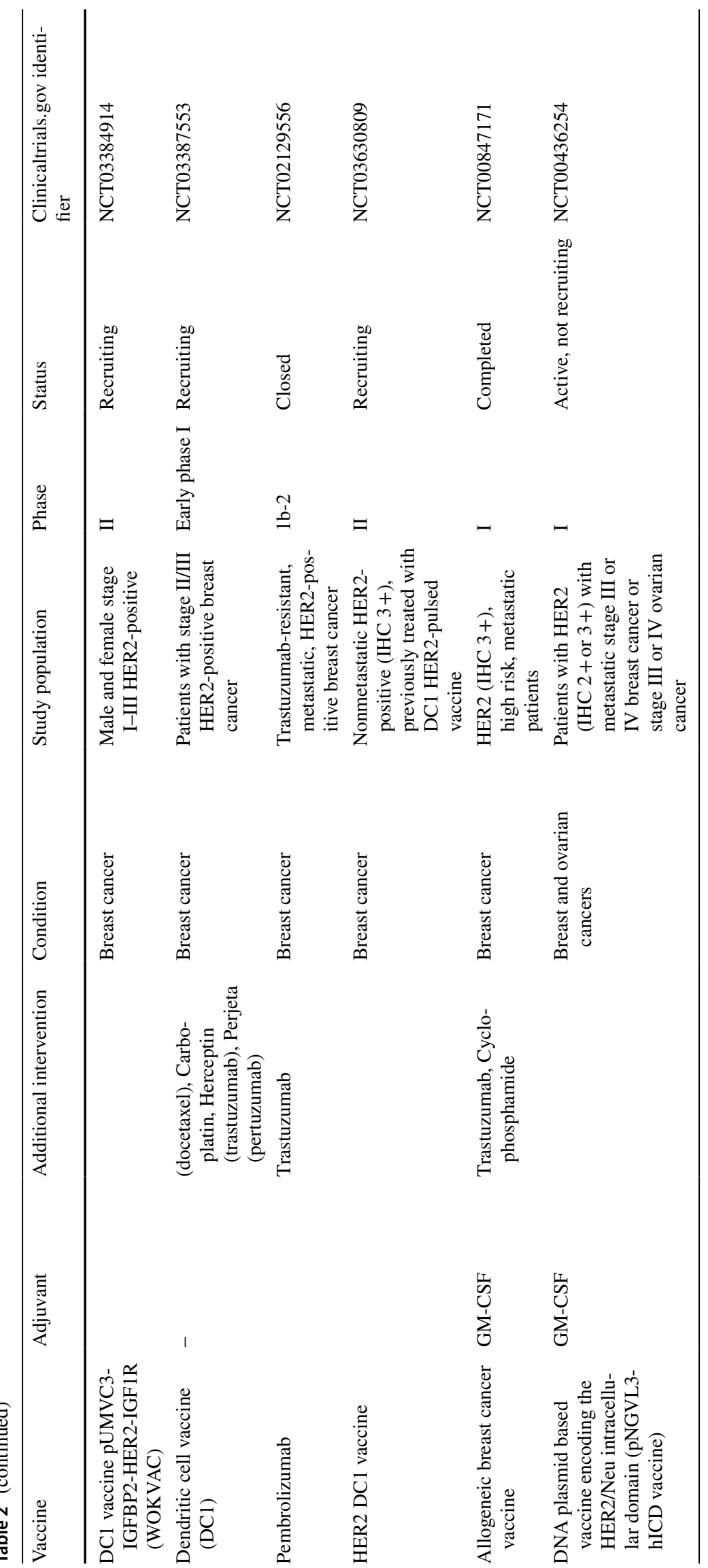


clinical trial to evaluate the efficacy and tolerability of a HER2 plasmid DNA vaccine in human was performed at the oncology clinic, Radiumhemmet, Karolinska University Hospital (Stockholm, Sweden). This pDNA vaccine encoded the total length of HER2 molecule. Eight patients with advanced/metastatic HER2 expressing breast cancer already on treatment with trastuzumab received the HER2/ neu pDNA vaccine with low doses of GM-CSF and IL-2. Six patients (out of eight) completed the three vaccination cycles in this study. The other two patients only received one dose of vaccine and due to complications and rapid development of the cancer no further doses were provided. In fact, one patient developed erysipelas (infection of the upper dermis and superficial lymphatics) and the other patient was withdrawn due to disease progression which might be due to the vaccine. The co-administration of HER2-pDNA vaccine plus GM-CSF, trastuzumab and IL-2 was well-tolerated with no acute toxicity, cardiotoxicity and autoimmunity. The level of specific $\mathrm{T}$ cells and antibodies against HER2 were increased significantly after vaccination and long-lasting cellular and humoral immunity were observed in some patients for several years. The median survival time for eight patients was 76 months with a range of 46-96 months (Norell et al. 2010). In another phase I clinical study, the safety and immunogenicity of a dual component human DNA vaccine named V930, and V932 were evaluated. V930 vaccine consisted of two plasmids expressing the ECD and transmembrane domains of HER2 and carcinoembryonic antigen (CEA) fusion B-subunit of Escherichia coli heat labile toxin (LTB) (study 1). The V932 used was an adenoviral vaccine vector encoding the CEA fusion LTB and the truncated HER2 (study 2). Patients with grade II, III or IV for breast, colon, ovary, or non-small cell lung cancers that expressed HER2 and/or (CEA) received these DNA vaccines. Both vaccines proved to be safe and tolerable. No cell-mediated responses to CEA or HER 2 was detectable in vaccinated patients. Only the immune response against bacterial portion of the vector was detected (Diaz et al. 2013).

Currently two phase I clinical trials using DNA vaccines for HER2 are active. One study is supported by Memorial Sloan Kettering Cancer Center (NCT00393783). The goal of this study is to assess the safety and type of immune responses by the rat HER2/neu vaccination in patients suffering from stage III or metastatic breast cancer (AJCC Stage III and IV) that overexpress HER2. In the second trial (NCT00436254), DNA coding the intracellular domain of HER2 cloned into a pNGVL3-hICD plasmid. Sixty-six patients with HER2 overexpressing cancer were enrolled. The subjects received pNGVL3-hICD vaccine combined with GM-CSF intradermal/month for three consecutive months. The adverse effects, the best dose of DNA vaccine which could elicit HER2 specific immune response was determined. The patients were monitored for up to 15 years by the physicians. Table 2 represents a list of clinical trials for HER2-positive types of cancer.

\section{Autologous Tumor Cell Vaccines}

Autologous tumor cell vaccine is a patient specific and safe approach for vaccine development by creating a personalized vaccine. Here the tumor cell lysates from a patient's own tumor antigens are exploited to develop an effective immune response. However, the major disadvantages of allogeneic tumor cell vaccine (ATCV) is the inherent poor immunogenicity of tumor cells and inconsistency of the production method (Parvizpour et al. 2018). In addition, due to the presence of endogenous cellular antigens, an autoimmune reaction is possible (Al-Awadhi et al. 2018; Kurtz et al. 2014). In ATCV based breast cancer immunotherapy, an additional antigen, immune modulator or cytokines is combined with the autologous breast tumor cell (Kurtz et al. 2014). Currently, in phase I clinical trials (two different studies), autologous breast cancer cells secreting GM-CSF are being evaluated for activation of immune responses. In one study (NCT00317603) the safety and biological activity of the vaccine is being evaluated in stage IV HER2 metastatic breast cancer patients previously treated with trastuzumab. In the second study (NCT00880464), the vaccine is being investigated in women with operable, stage II, III breast cancer. In another autologous active cellular immunotherapy, 18 patients with metastatic HER2 overexpressing breast cancer have been evaluated for the toxicity and the immune response induced by Lapuleucel-T (APC8024). This vaccine comprised of PBMCs, activated before with the recombinant fusion protein (the intra- and extracellular domains of HER2) plus GM-CSF. Significant anti-HER2 cellular response was observed and the vaccine was very well-tolerated. Three patients presented with disease stabilization for 1 year and partial tumor activity was observed in one patient after 6 months (Park et al. 2007). Early clinical trials of GM-CSF-secreting tumor vaccines demonstrated their safety, bioactivity and clinical benefits in solid tumors. However, vaccination alone is insufficient to induce an immune response (Jaffee et al. 2001; Laheru et al. 2008). Co-administration of some chemotherapeutic agents in proper doses and sequence can augment the immunotherapy. In an experimental work, GM-CSF whole cell vaccine with low doses of cyclophosphamide and doxorubicin induced HER2 specific immune response in HER2/neu (neu-N) transgenic mice (Machiels et al. 2001). Cyclophosphamide seems to inhibit $\mathrm{CD} 4{ }^{+} \mathrm{CD} 25^{+}$Treg cells activity and promote the activation of high-avidity specific CD ${ }^{+} \mathrm{T}$ cells (Ercolini et al. 2005). 


\section{Allogeneic Tumor Cell Vaccines}

Allogeneic and autologous vaccines are similar in most aspects but also present with some differences. Here tumor antigens are obtained from the same species cancerous cells grown in laboratory. Therefore, they are not patient specific (Srivatsan et al. 2014). Allogeneic vaccines have been studied alone or in combination therapy. An investigation was performed using either allogeneic GM-CSF-secreting breast cancer vaccine alone or in combination with limited doses of cyclophosphamide and doxorubicin. The study was designed to evaluate the adverse effects and immunologic activity of the vaccine and to determine the optimal chemotherapy dose in the combination therapy in HER2-positive breast cancer. This vaccine was made of two cell lines (T47D parent, HER $2^{\text {low }}$ ) and SKBR3 (HER2 ${ }^{\text {high }}$ ) which were modified genetically to secrete GM-SCF. Twenty-eight patients were administrated with vaccine alone or with cyclophosphamide and doxorubicin sequentially. The vaccine was safe and no dose limiting toxicity was observed. HER2 specific Th-dependent immunity was induced with vaccine alone or with low doses of chemotherapy agents. It was revealed that doses of $200 \mathrm{mg} \mathrm{m}^{2}$ and $35 \mathrm{mg} \mathrm{m}^{2}$ of cyclophosphamide and doxorubicin produced the highest humoral immunity responses. The results of this study suggested that low dose chemotherapy with cyclophosphamide and doxorubicin could break the immune tolerance, with constant immune responses toward specific antigen (Emens et al. 2009). In a phase II trial (NCT00847171), the activity of immune system in combination therapy with trastuzumab, cyclophosphamide and allogeneic GM-SCF secreting cell vaccine in patients with high risk or metastatic breast cancer was evaluated. Based on the vaccination strategy, patients received trastuzumab weekly at the beginning and continued until the completion of vaccination. Patients also received cyclophosphamide and allogeneic breast cancer vaccines expressing GM-CSF. No serious adverse effects were reported.

\section{Dendritic Cell Vaccines}

Dendritic cells also known as "professional APCs" have a central role in the immune system due to their functions in regulating immune tolerance and initiation of anti-tumor effects. Both during microbial or viral infection and cancer development, DCs can induce tumor-specific CTL responses by presenting the TAA to Tlymphocytes through the MHC I and II pathways (Palucka and Banchereau 2012). Moreover, DCs have crucial roles in controlling antibody-based responses. They are capable to interact with B cells directly and helping $\mathrm{B}$ cells by inducing the expansion and differentiation of $\mathrm{CD}^{+} \mathrm{T}$ cells, resulting in a raise of specific humoral immunity. Considering all these properties, DCs may be the best candidates in any therapeutic vaccination process leading to a strong immune response against cancer cells (Batista and Harwood 2009; Qi et al. 2006). DC-based vaccines have appeared to be more effective in improving cellular immunity in comparison to peptide-based vaccination approaches (Dissanayake et al. 2014). Growing data in preclinical and clinical experiments reveal that DC-based vaccines are capable to induce strong anti-tumor responses against breast cancer cells (Gelao et al. 2014). Transfection of DCs with specific mRNA, to drive adaptive immunity response, has confirmed to be an effective approach to induce expansion of $\mathrm{CD}^{+}$and $\mathrm{CD} 8^{+} \mathrm{T}$ cells. Bryson et al. (2017) prepared a multifunctional vaccine made from a modified lentivirus, loaded with two breast cancer antigens including alpha lactalbumin, and HER2, which could directly target the resident DCs. Single injections of the DCtargeted lentiviral vectors resulted in tumor self-antigen-specific cellular immunity, decreasing tumor development and rendering an effective immunotherapy for HER2-positive breast cancer (Bryson et al. 2017). Another preclinical study evaluated the efficacy of DCs transfected with an adenovirus expressing the HER2/neu gene (AdNeuTK) and IL-12. Subcutaneous immunization of Friend leukemia virus B (FVB) mice with the DC vaccine could provide anti-tumor immunity in about $60 \%$ of the mice under study. The result of in vivo depletion studies also established the role of both $\mathrm{CD}^{+}$and $\mathrm{CD}^{+}{ }^{+}$cells in inducing anti-tumor immunity (Chen et al. 2001). Xie et al. (2013) engineered DCs with two cancer antigens including the $\mathrm{P} 30$ peptide-derived from tetanus toxin (FNNFTVSFWLRVPKVSASHLE) and HER2derived peptides to generate highly efficient $\mathrm{CD} 4^{+}$and $\mathrm{CD} 8^{+}$ $\mathrm{T}$ cell responses toward HER2-positive breast cancer. In another report, Viehl et al. (2005) indicated that administration of DCs transfected with HER2 fused to Tat protein led to protection effects against tumor in FVB/N mice challenged with syngeneic HER 2 overexpressing breast cancer cells. Authors found that immunization of the mice with TatHER2/neu transduced DCs considerably resulting in smaller sizes of the tumor compared to the control group or to mice received DCs transfected with Tat. Both $\mathrm{CD} 4^{+}$and $\mathrm{CD} 8^{+} \mathrm{T}$ responses were essential to prompt this anti-tumor response (Viehl et al. 2005). Objective clinical responses also have been observed in some patients with HER2-positive breast cancer. In the results of clinical trial reported by Czerniecki et al. (2007) thirteen patients with HER2-positive breast cancer vaccinated with DCs loaded HER2/neu HLA class I and II peptides weekly repeated four times before surgery. Immune response against the peptides observed for both IFN- $\gamma$-secreting $\mathrm{CD}^{+}(85 \%)$ and $\mathrm{CD}^{+}(80 \%) \mathrm{T}$ lymphocyte cells (Czerniecki et al. 2007). Although multiple approaches such as selection of the suitable DC subsets, adjuvants and the augmentation of DC functionalities are being assessed to develop the efficiency of DC-based vaccines, but their clinical benefits are still limited. 


\section{Other Targets for Breast Cancer Vaccine Development}

Due to the increasing interest in breast cancer immunotherapy research, in addition to HER2 receptor other molecules such as MUC-1 have been extensively studied shown promising success rates. Mucin or MUC-1 is a transmembrane glycoprotein expressed in the breast, lung, colon, ovary, pancreas and other tissues. The extracellular domain of MUC-1 has a variable number of 20 amino acid tandem repeat units which are highly glycosylated in normal cells, but either hypo-glycosylated or aberrantly glycosylated in cancerous cells. This difference presentation of MUC-1 between normal and abnormal cells makes it an attractive target for immunotherapy (Hossain and Wall 2016). T cells recognizing MUC-1 have been derived from the blood of patients with breast cancer (Disis et al. 1994; Jerome et al. 1993). MUC-1 is overexpressed in more than $90 \%$ of breast cancer cells and has a correlation with HER2. In fact, silencing of MUC-1 down-regulate HER2 activation and reverses resistance to trastuzumab (Raina et al. 2014). The most difficult situation for patients with HER2 overexpression is resistance to trastuzumab. Go-203, a MUC-1 inhibitor (Raina et al. 2009) can disrupt MUC-1/HER2 complexes and decrease HER 2 phosphorylation. It has been found that a combination therapy with GO-203 and trastuzumab have synergistic effects in HER2-positive breast cancer (Raina et al. 2014). In many clinical studies, the safety and immunologic responses both cellular and humoral responses against MUC-1 in patients with breast carcinoma were demonstrated (Ko et al. 2003).Vaccines designed to target MUC-1 have been used with different carriers such as keyhole limpet hemocyanin (KLH), bovine serum albumin and tetanus toxoid with adjuvants including, monophosphoryl lipid A, Quillaja saponaria extract (QS)-21, Bacillus Calmette-Guerin or incomplete Freund's adjuvant to boost immune responses (Hossain and Wall 2016). In one study, patients with highrisk breast cancer were vaccinated with MUC1-KLH conjugated to QS-21. Patients developed adverse effects such as local skin reactions and mild flu like symptoms. IgG and $\operatorname{IgM}$ antibodies titers were increased following the vaccination. Nevertheless, no data about $\mathrm{T}$ cell responses was presented (Gilewski et al. 2000). In a phase I/II, nine patients with metastatic breast cancer were inoculated with a recombinant vaccine virus expressing the human MUC-1 plus IL-2 gene (TG1031). Although MUC-1-specific antibody not measured in any of the patients but in two patients MUC-1-specific CTLs was detected. Also, evidence of the presence of T memory cells in tumor biopsies was observed (Scholl et al. 2000). In a phase III, 29 subjects with grade II breast cancer received either placebo or manna-oxidized MUC-1. The patient responses were assessed based on prevention of recurrence or metastatic cancer. No recurrence was reported in the immunotherapy group (0/16) versus $27 \%$
(4/15) in the placebo group after more than 5.5 years follow up. Measurable anti-MUC-1 antibody titers and T cell response were determined in vaccinated patients (Apostolopoulos et al. 2006). The follow up of study for 15 years indicated that about $60 \%$ and $12.5 \%$ recurrence of the disease was possible in placebo and immunized group, respectively (Vassilaros et al. 2007).

\section{Viral Oncotherapy}

A minority of HER2-positive breast cancer patients do not respond to targeted $\mathrm{mAb}$ therapies because of resistance to HER2 antibodies or due to the inaccessibility of anti-HER2 antibodies (brain metastases). Therefore, in a similar line of research into vaccine development, other new therapeutic modalities are needed (Eager and Nemunaitis 2011).

Recently, an increasing number of oncolytic viruses have been developed for treating different types of cancers (Miest and Cattaneo 2014). Preclinical in vivo experiments with viruses have been carried out for breast cancer HER2. For example, Nanni et al. (2013) prevented the development of HER2 ovarian and breast metastatic tumors using a HER2 targeted oncolytic virus. The first oncolytic herpes simplex virus fully detargetted from both nectin 1 and herpes virus entry mediator and retargeted to the human oncoprotein HER2 reported by Menotti et al. (2009). Here the Ig-folded core in the receptor-binding virion glycoprotein $\mathrm{gD}$ was replaced with anti-HER2 single-chain antibody. Authors showed that intra-tumoral administration of HSV in nude mice bearing HER2-overexpressing human tumors, stopped the outgrowth of highly progressive tumor (Menotti et al. 2009).

\section{Immune Checkpoint Inhibitors}

Cancer immunotherapy through immune checkpoint receptors on $\mathrm{T}$ cell surface has already assessed in a range of tumor types, such as breast cancer, head and neck cancer as well as melanoma, some advanced solid and hematological malignancies and non-small cell lung cancer and is quickly changing the practice of medical oncology (Alsaab et al. 2017). The two main immune inhibitory pathways of T cell activation in the context of clinical cancer immunotherapy, PD-1/PD-L1 or PD-L2 and CTLA-4, play unique roles in regulating immunity (Khedri et al. 2011; Yazdian-Robati et al. 2017). Blocking these pathways via mAbs or aptamers provoke significant anti-tumor activities in numerous tumors including breast cancer (Dollins et al. 2008). Kim et al. (2017) evaluated PD-L1 protein expression, the level of PD-L1 mRNA and different histopathologic elements including TILs utilizing fresh and formalin-fixed paraffin embedded HER2-positive breast cancer tissues. They found higher mutational burden, greater numbers of TILs 
and significant rates of PD-L1 positivity in HER2-positive cancers (Kim et al. 2017). For the first time, in a preclinical study the effectiveness of PD-L1 immune checkpoint blockade and whole cell vaccination in a HER2-positive mouse model of breast cancer showed complete tumor regression in $50 \%$ of the treated mice (Bozeman et al. 2016; Nourbakhsh et al. 2015). Blocking CTLA-4 using ipilimumab has revealed encouraging results in a phase III study (Wolchok et al. 2013). The combination of ado-trastuzumab emtansine with both anti-CTLA4 and anti-PD-1 mAbs, in orthotopic mouse models of HER 2 breast cancer, improved innate and adaptive anti-tumor immune responses relative to trastuzumab emtansine (TDM1) or immunotherapy alone and resulted in overcoming the primary resistance to immune checkpoint-blocking antibodies (Müller et al. 2015). In one study reported by Gao et al. (2009) a recombinant oncolytic virus was employed in a combination of a CTLA- 4 antibody to preferentially target HER 2 breast cancer cells. This combination therapy could cure the majority of the mice, while the virotherapy alone prolonged only the survival time (Gao et al. 2009).

Numerous clinical trials are in progress to assess the addition of PD-1/PD-L1 antibodies to other HER2 based therapies (Table 2). In a clinical phase $1 \mathrm{~b}-2$ trial (PANACEA), the safety and clinical outcome of combination therapy of pembrolizumab (PD-1 blocker) plus trastuzumab in women with trastuzumab-resistant, metastatic, HER2-positive breast cancer was assessed. Findings of this study confirmed the clinical benefits of the treatment. No dose limiting toxicities were observed (Loi et al. 2019).

A double blinded phase II trial is now underway to test whether the combination of atezolizumab to TDM1 can further increase clinical effects in participants with metastatic HER 2 breast cancer previously treated with trastuzumab and a taxane (NCT02924883). In another randomized clinical trial the activity of three different combination drugs are being evaluated: (1) trastuzumab and vinorelbine combined, (2) trastuzumab, vinorelbine and avelumab (mAb directed against the PD-L1) combined, and (3) trastuzumab, vinorelbine, avelumab and utomilumab combined in progressive HER2-positive breast cancer (NCT03414658).

\section{Conclusions and Future Perspective}

Immunotherapy is a promising approach for managing breast cancer, particularly when combined with other standard therapies such as surgery, chemotherapy, radiation and hormonal therapy. Immunotherapy with trastuzumab has provided a proven efficacy in HER2-positive breast cancer patients as monotherapy or in combination with chemotherapeutic agents. Although trastuzumab is well-tolerated, but the acquired resistance and its cardiotoxicity are serious concerns in clinic.
Active immunotherapy with several advantages over passive immunotherapy or chemotherapy, can be used as a combination to the other modalities. In vaccination the induction of immune responses is tumor specific and usually well tolerated. The most important aspect of active immunotherapy and anticancer vaccination is the provision of long-lasting immunity against tumor antigens and thus preventing tumor relapse. Many clinical trials have been conducted using HER2 peptidebased vaccines alone or in combination with trastuzumab. NeuVax (E75) is a well-studied HER2 peptide-based vaccine in phase III clinical trial and has been studied in combination with trastuzumab in phase II. Other peptides, GP2 and AE37 are also being studied in clinical trial phase II. Although there are positive reports coming out of these clinical trials, overall no specific immunotherapy approach has been approved for HER2-positive breast cancer yet. Several limitations of HER2 peptide vaccines strategies are noted: (1) E75 peptide is a HLA-A2 and HLA-A3 restricted peptide, thus limited number of patients who are HLA-A2 and HLA-A3-positive will benefit from this type of vaccine; (2) the immunity induced by E75 and GP2 is short-lived and need booster doses to generate long-lasting memory immune cells; (3) developing of immune tolerance against HER2 antigens is possible; and (4) there is an unfavorable impact of chemotherapy and radiation therapy on immune system before vaccination. Strategies using HER2positive whole tumor vaccine or antigen-encoding DNA vaccine could provide multiple epitopes and stimulate immune response strongly against HER2-positive tumor. However, concerns about serious adverse effects and high risk of autoimmunity hinder their clinical development and investigation about them still is remained in early experimental stage. The ability to overwhelmed $\mathrm{T}$ cell anergy using immune checkpoint inhibitors including CTLA-4 or PD-1/PD-L1 has shown promise for HER2-positive breast cancer treatment, demonstrating the potential to harness the immune system but this approach is still relatively nonspecific. It seems that applying vaccination approach integrated with other standard therapies will certainly bring us closer to the final goal of immune-based breast cancer prevention.

\section{Compliance with Ethical Standards}

Conflict of interest Javad Behravan is an adjunct professor at University of Waterloo, Waterloo, Ontario, Canada and Co-founder of Theraphage Inc. Kitchener, Ontario, Canada. The authors declare that they have no conflicts of interests.

\section{References}

Aboud-Pirak E, Hurwitz E, Pirak ME et al (1988) Efficacy of antibodies to epidermal growth factor receptor against $\mathrm{KB}$ carcinoma in vitro and in nude mice. J Natl Cancer Inst 80:1605-1611 
Al-Awadhi A, Lee Murray J, Ibrahim NK (2018) Developing antiHER 2 vaccines: B reast cancer experience. Int J Cancer 143:2126-2132

Alexe G, Dalgin GS, Scanfeld D et al (2007) High expression of lymphocyte-associated genes in node-negative HER2 + breast cancers correlates with lower recurrence rates. Cancer Res 67:10669-10676

Alsaab HO, Sau S, Alzhrani R et al (2017) PD-1 and PD-L1 checkpoint signaling inhibition for cancer immunotherapy: mechanism, combinations, and clinical outcome. Front Pharmacol 8:561

Alving CR (1991) Liposomes as carriers of antigens and adjuvants. J Immunol Methods 140:1-13

Apostolopoulos V, Pietersz GA, Tsibanis A et al (2006) Pilot phase III immunotherapy study in early-stage breast cancer patients using oxidized mannan-MUC1 [ISRCTN71711835]. Breast Cancer Res 8:R27

Arab A, Behravan J, Razazan A et al (2018a) A nano-liposome vaccine carrying E75, a HER-2/neu-derived peptide, exhibits significant antitumour activity in mice. J Drug Target 26:365-372

Arab A, Nicastro J, Slavcev R et al (2018b) Lambda phage nanoparticles displaying HER2-derived E75 peptide induce effective E75-CD8 + T response. Immunol Res 66:200-206

Arab A, Robati RY, Nicastro J et al (2018c) Phage-based nanomedicines as new immune therapeutic agents for breast cancer. Curr Pharm Des 24:1195-1203

Arab A, Behravan N, Razazn A et al (2019) The viral approach to breast cancer immunotherapy. J Cell Physiol 234:1257-1267

Arteaga CL, Winnier AR, Poirier MC et al (1994) p185c-erbB-2 signaling enhances cisplatin-induced cytotoxicity in human breast carcinoma cells: association between an oncogenic receptor tyrosine kinase and drug-induced DNA repair. Cancer Res 54:3758-3765

Ayoub NM, Al-Shami KM, Yaghan RJ (2019) Immunotherapy for HER2-positive breast cancer: recent advances and combination therapeutic approaches. Breast Cancer 11:53-69

Barati N, Nikpoor AR, Razazan A et al (2017) Nanoliposomes carrying HER2/neu-derived peptide AE36 with CpG-ODN exhibit therapeutic and prophylactic activities in a mice TUBO model of breast cancer. Immunol Lett 190:108-117

Barati N, Razazan A, Nicastro J et al (2018) Immunogenicity and antitumor activity of the superlytic $\lambda F 7$ phage nanoparticles displaying a HER2/neu-derived peptide AE37 in a tumor model of BALB/c mice. Cancer Lett 424:109-116

Batista FD, Harwood NE (2009) The who, how and where of antigen presentation to B cells. Nat Rev Immunol 9:15-27

Behravan J, Razazan A, Behravan G (2018) Towards breast cancer vaccines, progressand challenges. Curr Drug Discov Technol. https ://doi.org/10.2174/1570163815666180502164652

Benavides L, Holmes J, Gates J et al (2008) Results of the first phase I clinical trial of the novel Ii-key hybrid preventive HER2/neu peptide (AE37) vaccine: United States Military Cancer Institute Clinical Trials Group Study I-03. J Clin Oncol 26:3016

Bi J, Zhao J, Bao L et al (2008) Preparation and anti-tumor evaluation of polyactin A microparticles from supercritical $\mathrm{CO}_{2}$ processing. Appl Surf Sci 255:320-323

Bozeman EN, He S, Shafizadeh Y et al (2016) Therapeutic efficacy of PD-L1 blockade in a breast cancer model is enhanced by cellular vaccines expressing B7-1 and glycolipid-anchored IL-12. Hum Vaccin Immunother 12:421-430

Brossart P, Stuhler G, Flad T et al (1998) Her-2/neu-derived peptides are tumor-associated antigens expressed by human renal cell and colon carcinoma lines and are recognized by in vitro induced specific cytotoxic T lymphocytes. Cancer Res 58:732-736

Bryson PD, Han X, Truong N et al (2017) Breast cancer vaccines delivered by dendritic cell-targeted lentivectors induce potent antitumor immune responses and protect mice from mammary tumor growth. Vaccine 35:5842-5849
Carmichael MG, Benavides LC, Holmes JP et al (2010) Results of the first phase 1 clinical trial of the HER-2/neu peptide (GP2) vaccine in disease-free breast cancer patients: United States Military Cancer Institute Clinical Trials Group Study I-04. Cancer 116:292-301

Chen Y, Hu D, Eling DJ et al (1998) DNA vaccines encoding fulllength or truncated Neu induce protective immunity against Neuexpressing mammary tumors. Cancer Res 58:1965-1971

Chen Y, Emtage P, Zhu Q et al (2001) Induction of ErbB-2/neu-specific protective and therapeutic antitumor immunity using genetically modified dendritic cells: enhanced efficacy by cotransduction of gene encoding IL-12. Gene Ther 8:316-323

Chin Y, Janseens J, Vandepitte J et al (1992) Phenotypic analysis of tumor-infiltrating lymphocytes from human breast cancer. Anticancer Res 12:1463-1466

Clifton GT, Gall V, Peoples GE et al (2016) Clinical development of the E75 vaccine in breast cancer. Breast Care 11:116-121

Clifton GT, Peace KM, Holmes JP et al (2019) Initial safety analysis of a randomized phase II trial of nelipepimut-S + GM-CSF and trastuzumab compared to trastuzumab alone to prevent recurrence in breast cancer patients with HER2 low-expressing tumors. Clin Immunol 201:48-54

Clive KS, Tyler JA, Clifton GT et al (2012) The GP2 peptide: a HER2/ neu-based breast cancer vaccine. J Surg Oncol 105:452-458

Costa R, Soliman H, Czerniecki B (2017) The clinical development of vaccines for HER2 + breast cancer: current landscape and future perspectives. Cancer Treat Rev 61:107-115

Cruz JSD, Lau SY, Ramirez EM et al (2003) Protein vaccination with the HER2/neu extracellular domain plus anti-HER2/neu antibody-cytokine fusion proteins induces a protective anti-HER2/ neu immune response in mice. Vaccine 21:1317-1326

Cui N, Shi J, Yang C (2018) HER2-based immunotherapy for breast cancer. Cancer Biother Radiopharm 33:169-175

Curigliano G, Romieu G, Campone M et al (2016) A phase I/II trial of the safety and clinical activity of a HER2-protein based immunotherapeutic for treating women with HER2-positive metastatic breast cancer. Breast Cancer Res Treat 156:301-310

Czerniecki BJ, Koski GK, Koldovsky U et al (2007) Targeting HER-2/ neu in early breast cancer development using dendritic cells with staged interleukin-12 burst secretion. Cancer Res 67:1842-1852

Datta J, Xu S, Rosemblit C et al (2015) CD4+T-helper type 1 cytokines and trastuzumab facilitate CD8+ T cell targeting of HER2/neuexpressing cancers. Cancer Immunol Res 3:455-463

Datta J, Fracol M, McMillan MT et al (2016) Association of depressed anti-HER2 T-helper type 1 response with recurrence in patients with completely treated HER2-positive breast cancer: role for immune monitoring. JAMA Oncol 2:242-246

De La Cruz LM, Nocera NF, Czerniecki BJ (2016) Restoring antioncodriver Th1 responses with dendritic cell vaccines in HER2/ neu-positive breast cancer: progress and potential. Immunotherapy 8:1219-1232

Diaz CM, Chiappori A, Aurisicchio L et al (2013) Phase 1 studies of the safety and immunogenicity of electroporated HER2/CEA DNA vaccine followed by adenoviral boost immunization in patients with solid tumors. J Transl Med 11:62

Disis ML, Calenoff E, McLaughlin G et al (1994) Existent T cell and antibody immunity to HER-2/neu protein in patients with breast cancer. Cancer Res 54:16-20

Disis ML, Grabstein KH, Sleath PR et al (1999) Generation of immunity to the HER-2/neu oncogenic protein in patients with breast and ovarian cancer using a peptide-based vaccine. Clin Cancer Res 5:1289-1297

Disis ML, Schiffman K, Guthrie K et al (2004) Effect of dose on immune response in patients vaccinated with an her-2/neu intracellular domain protein-based vaccine. J Clin Oncol 22:1916-1925 
Dissanayake D, Murakami K, Tran MD et al (2014) Peptide-pulsed dendritic cells have superior ability to induce immune-mediated tissue destruction compared to peptide with adjuvant. PLoS One 9:e92380

Dollins CM, Nair S, Sullenger BA (2008) Aptamers in immunotherapy. Hum Gene Ther 19:443-450

Doyle HA, Koski RA, Bonafé N et al (2018) Epidermal growth factor receptor peptide vaccination induces cross-reactive immunity to human EGFR, HER2, and HER3. Cancer Immunol Immunother 67:1559-1569

Eager R, Nemunaitis J (2011) Clinical development directions in oncolytic viral therapy. Cancer Gene Ther 18:305-317

Elahian F, Kalalinia F, Behravan J (2009) Dexamethasone downregulates BCRP mRNA and protein expression in breast cancer cell lines. Oncol Res 18(1):9-15

Emens LA, Asquith JM, Leatherman JM et al (2009) Timed sequential treatment with cyclophosphamide, doxorubicin, and an allogeneic granulocyte-macrophage colony-stimulating factorsecreting breast tumor vaccine: a chemotherapy dose-ranging factorial study of safety and immune activation. J Clin Oncol 27:5911-5918

Ercolini AM, Ladle BH, Manning EA et al (2005) Recruitment of latent pools of high-avidity CD8 $+\mathrm{T}$ cells to the antitumor immune response. J Exp Med 201:1591-1602

Fisk B, Savary C, Hudson JM et al (1995) Changes in an HER-2 peptide upregulating HLA-A2 expression affect both conformational epitopes and CTL recognition: implications for optimization of antigen presentation and tumor-specific CTL induction. J Immunother Emphasis Tumor Immunol 18:197-209

Förster R, Davalos-Misslitz AC, Rot A (2008) CCR7 and its ligands: balancing immunity and tolerance. Nat Rev Immunol 8:362-371

Franklin MC, Carey KD, Vajdos FF et al (2004) Insights into ErbB signaling from the structure of the ErbB2-pertuzumab complex. Cancer Cell 5:317-328

Frenzel A, Schirrmann T, Hust M (2016) Phage display-derived human antibodies in clinical development and therapy. MAbs 8:1177-1194

Gao Y, Whitaker-Dowling P, Griffin J et al (2009) Recombinant vesicular stomatitis virus targeted to Her2/neu combined with antiCTLA4 antibody eliminates implanted mammary tumors. Cancer Gene Ther 16:44-52

Gelao L, Criscitiello C, Esposito A et al (2014) Dendritic cell-based vaccines: clinical applications in breast cancer. Immunotherapy 6:349-360

Gilewski T, Adluri S, Ragupathi G et al (2000) Vaccination of highrisk breast cancer patients with mucin-1 (MUC1) keyhole limpet hemocyanin conjugate plus QS-21. Clin Cancer Res 6:1693-1701

Gillogly ME, Kallinteris NL, Xu M et al (2004) Ii-Key/HER-2/neu MHC class-II antigenic epitope vaccine peptide for breast cancer. Cancer Immunol Immunother 53:490-496

Holmes JP, Benavides LC, Gates JD et al (2008) Results of the first phase I clinical trial of the novel II-key hybrid preventive HER-2/ neu peptide (AE37) vaccine. J Clin Oncol 26:3426-3433

Hossain M, Wall K (2016) Immunological evaluation of recent MUC1 glycopeptide cancer vaccines. Vaccines 4(3):E25

Huang Y, Ma C, Zhang Q et al (2015) CD4 + and CD8 + T cells have opposing roles in breast cancer progression and outcome. Oncotarget 6:17462-17478

Jacob J, Radkevich O, Forni G et al (2006) Activity of DNA vaccines encoding self or heterologous Her-2/neu in Her-2 or neu transgenic mice. Cell Immunol 240:96-106

Jaffee EM, Hruban RH, Biedrzycki B et al (2001) Novel allogeneic granulocyte-macrophage colony-stimulating factor-secreting tumor vaccine for pancreatic cancer: a phase I trial of safety and immune activation. J Clin Oncol 19:145-156
Jerome K, Domenech N, Finn O (1993) Tumor-specific cytotoxic T cell clones from patients with breast and pancreatic adenocarcinoma recognize EBV-immortalized B cells transfected with polymorphic epithelial mucin complementary DNA. J Immunol 151:1654-1662

Jinushi M (2015) Immune regulation of cancer stem cells. Nihon Rinsho 73:795-799

Kageyama S, Kitano S, Hirayama M et al (2008) Humoral immune responses in patients vaccinated with 1-146 HER2 protein complexed with cholesteryl pullulan nanogel. Cancer Sci 99:601-607

Kawashima I, Hudson SJ, Tsai V et al (1998) The multi-epitope approach for immunotherapy for cancer: identification of several CTL epitopes from various tumor-associated antigens expressed on solid epithelial tumors. Hum Immunol 59:1-14

Khedri A, Nejat-Shokouhi A, Salek R et al (2011) Association of the colorectal cancer and MDR1 gene polymorphism in an Iranian population. Mol Biol Reports 38(5):2939-2943

Kim JH, Majumder N, Lin H et al (2005) Enhanced immunity by NeuEDhsp70 DNA vaccine is needed to combat an aggressive spontaneous metastatic breast cancer. Mol Ther 11:941-949

Kim E, Seo H, Chae M et al (2014) Enhanced antitumor immunotherapeutic effect of B-cell-based vaccine transduced with modified adenoviral vector containing type 35 fiber structures. Gene Ther $21: 106-114$

Kim A, Lee SJ, Kim YK et al (2017) Programmed death-ligand 1 (PDL1) expression in tumour cell and tumour infiltrating lymphocytes of HER2-positive breast cancer and its prognostic value. Sci Rep 7:11671

Kitano S, Kageyama S, Nagata Y et al (2006) HER2-specific T cell immune responses in patients vaccinated with truncated HER2 protein complexed with nanogels of cholesteryl pullulan. Clin Cancer Res 12:7397-7405

Knutson KL, Clynes R, Shreeder B et al (2016) Improved survival of HER 2 + breast cancer patients treated with trastuzumab and chemotherapy is associated with host antibody immunity against the HER2 intracellular domain. Cancer Res 76:3702-3710

Ko BK, Kawano K, Murray JL et al (2003) Clinical studies of vaccines targeting breast cancer. Clin Cancer Res 9:3222-3234

Krishnamachari Y, Geary SM, Lemke CD et al (2011) Nanoparticle delivery systems in cancer vaccines. Pharm Res 28:215-236

Kroemer G, Senovilla L, Galluzzi L et al (2015) Natural and therapy-induced immunosurveillance in breast cancer. Nat Med 21:1128-1138

Kuerer HM, Peoples GE, Sahin AA et al (2002) Axillary lymph node cellular immune response to HER-2/neu peptides in patients with carcinoma of the breast. J Interferon Cytokine Res 22:583-592

Kurtz SL, Ravindranathan S, Zaharoff DA (2014) Current status of autologous breast tumor cell-based vaccines. Expert Rev Vaccines 13:1439-1445

Ladjemi MZ, Jacot W, Chardès T et al (2010) Anti-HER2 vaccines: new prospects for breast cancer therapy. Cancer Immunol Immunother 59:1295-1312

Ladjemi MZ, Chardes T, Corgnac S et al (2011) Vaccination with human anti-trastuzumab anti-idiotype scFv reverses HER2 immunological tolerance and induces tumor immunity in MMTV. f. huHER2 (Fo5) mice. Breast Cancer Res 13:R17

Laheru D, Lutz E, Burke J et al (2008) Allogeneic granulocyte macrophage colony-stimulating factor-secreting tumor immunotherapy alone or in sequence with cyclophosphamide for metastatic pancreatic cancer: a pilot study of safety, feasibility, and immune activation. Clin Cancer Res 14:1455-1463

Leung HW, Chan AL, Muo CH et al (2018) Cost-effectiveness of pertuzumab combined with trastuzumab and docetaxel as a first-line treatment for HER-2 positive metastatic breast cancer. Expert Rev Pharmacoecon Outcomes Res 18:207-213 
Li L, Saade F, Petrovsky N (2012) The future of human DNA vaccines. J Biotechnol 162:171-182

Loi S, Giobbie-hurder A, Gombos A et al (2019) Pembrolizumab plus trastuzumab in trastuzumab-resistant, advanced, HER2-positive breast cancer (PANACEA): a single-arm, multicentre, phase 1b-2 trial. Lancet Oncol 20:371-382

Lollini PL, De Giovanni C, Pannellini T et al (2005) Cancer immunoprevention. Future Oncol 1:57-66

Machiels JP, Reilly RT, Emens LA et al (2001) Cyclophosphamide, doxorubicin, and paclitaxel enhance the antitumor immune response of granulocyte/macrophage-colony stimulating factorsecreting whole-cell vaccines in HER-2/neu tolerized mice. Cancer Res 61:3689-3697

Marchini C, Kalogris C, Garulli C et al (2013) Tailoring DNA vaccines: designing strategies against HER2-positive cancers. Front Oncol 3:122

Marmé F (2016) Immunotherapy in breast cancer. Oncol Res Treat 39:335-345

McCarthy EF (2006) The toxins of William B. Coley and the treatment of bone and soft-tissue sarcomas. Iowa Orthop J 26:154-158

Menotti L, Nicoletti G, Gatta V et al (2009) Inhibition of human tumor growth in mice by an oncolytic herpes simplex virus designed to target solely HER-2-positive cells. Proc Natl Acad Sci USA 106:9039-9044

Miest TS, Cattaneo R (2014) New viruses for cancer therapy: meeting clinical needs. Nat Rev Microbiol 12:23-34

Miliotou AN, Papadopoulou LC (2018) CAR T cell therapy: a new era in cancer immunotherapy. Curr Pharm Biotechno 19:5-18

Mittendorf EA, Storrer CE, Foley RJ et al (2006) Evaluation of the HER2/neu-derived peptide GP2 for use in a peptide-based breast cancer vaccine trial. Cancer 106:2309-2317

Mittendorf EA, Clifton GT, Holmes JP et al (2012) Clinical trial results of the HER-2/neu (E75) vaccine to prevent breast cancer recurrence in high-risk patients: from US Military Cancer Institute Clinical Trials Group Study I-01 and I-02. Cancer 118:2594-2602

Mittendorf E, Clifton G, Holmes J et al (2014) Final report of the phase I/II clinical trial of the E75 (nelipepimut-S) vaccine with booster inoculations to prevent disease recurrence in high-risk breast cancer patients. Ann Oncol 25:1735-1742

Mittendorf BA, Schneble EJ, Ibrahim NK et al (2015) Combination immunotherapy with trastuzumab and the HER2 vaccine E75 (nelipepimut-S) in high-risk HER2 + breast cancer patients to prevent recurrence. Cancer Res 75(Supp 9)

Mittendorf EA, Ardavanis A, Litton JK et al (2016) Primary analysis of a prospective, randomized, single-blinded phase II trial evaluating the HER2 peptide GP2 vaccine in breast cancer patients to prevent recurrence. Oncotarget 7:66192-66201

Mosaffa F, Kalalinia F, Lage H et al (2012) Pro-inflammatory cytokines interleukin-1 beta, interleukin 6 , and tumor necrosis factor-alpha alter the expression and function of ABCG2 in cervix and gastric cancer cells. Mol Cell Biochem 363:385-393

Mukai K, Yasutomi Y, Watanabe M et al (2002) HER2 peptide-specific $\mathrm{CD} 8+\mathrm{T}$ cells are proportionally detectable long after multiple DNA vaccinations. Gene Ther 9:879

Müller P, Kreuzaler M, Khan T et al (2015) Trastuzumab emtansine (T-DM1) renders HER2 + breast cancer highly susceptible to CTLA-4/PD-1 blockade. Sci Transl Med 7:315ra188-315ra188

Nami B, Maadi H, Wang Z (2018) Mechanisms underlying the action and synergism of trastuzumab and pertuzumab in targeting HER2-positive breast cancer. Cancers 10(10):E342

Nanda NK, Sercarz EE (1995) Induction of anti-self-immunity to cure cancer. Cell 82:13-17

Nanni P, Gatta V, Menotti L et al (2013) Preclinical therapy of disseminated HER-2 + ovarian and breast carcinomas with a HER2-retargeted oncolytic herpesvirus. PLoS Pathog 9:e1003155
Nazarkina ZK, Khar'kova M, Antonets D et al (2016) Design of polyepitope DNA vaccine against breast carcinoma cells and analysis of its expression in dendritic cells. Bull Exp Biol Med 160:486-490

Nguyen-Hoai T, Baldenhofer G, Ahmed MS et al (2012a) CCL21 (SLC) improves tumor protection by a DNA vaccine in a Her2/ neu mouse tumor model. Cancer Gene Ther 19:69-76

Nguyen-Hoai T, Hohn O, Vu M et al (2012b) CCL19 as an adjuvant for intradermal gene gun immunization in a Her2/neu mouse tumor model: improved vaccine efficacy and a role for B cells as APC. Cancer Gene Ther 19:880

Nordly P, Madsen HB, Nielsen HM et al (2009) Status and future prospects of lipid-based particulate delivery systems as vaccine adjuvants and their combination with immunostimulators. Expert Opin Drug Deliv 6:657-672

Norell H, Poschke I, Charo J et al (2010) Vaccination with a plasmid DNA encoding HER-2/neu together with low doses of GM-CSF and IL-2 in patients with metastatic breast carcinoma: a pilot clinical trial. J Transl Med 8:53

Nourbakhsh M, Jaafari MR, Lage H et al (2015) Nanolipoparticlesmediated MDR1 siRNA delivery reduces doxorubicin resistance in breast cancer cells and silences MDR1 expression in xenograft model of human breast cancer. Iran J Basic Med Sci 18(4):385-392

Pakravan N, Langroudi L, Hajimoradi M et al (2010) Co-administration of GP96 and Her2/neu DNA vaccine in a Her2 breast cancer model. Cell Stress Chaperones 15:977-984

Palucka K, Banchereau J (2012) Cancer immunotherapy via dendritic cells. Nat Rev Cancer 12:265-277

Park JW, Melisko ME, Esserman LJ et al (2007) Treatment with autologous antigen-presenting cells activated with the HER-2-based antigen lapuleucel-T: results of a phase I study in immunologic and clinical activity in HER-2-overexpressing breast cancer. J Clin Oncol 25:3680-3687

Parvizpour S, Razmara J, Omidi Y (2018) Breast cancer vaccination comes to age: impacts of bioinformatics. BioImpacts 8:223-235

Patil R, Clifton GT, Holmes JP et al (2010) Clinical and immunologic responses of HLA-A3 + breast cancer patients vaccinated with the HER2/neu-derived peptide vaccine, E75, in a phase I/II clinical trial. J Am Coll Surg 210:140-147

Peiper M, Goedegebuure PS, Linehan DC et al (1997) The HER2/ neu-derived peptide p654-662 is a tumor-associated antigen in human pancreatic cancer recognized by cytotoxic $\mathrm{T}$ lymphocytes. Eur J Immunol 27:1115-1123

Pietras R, Fendly B, Chazin V et al (1994) Antibody to HER-2/neu receptor blocks DNA repair after cisplatin in human breast and ovarian cancer cells. Oncogene 9:1829-1838

Pietras RJ, Pegram MD, Finn RS et al (1998) Remission of human breast cancer xenografts on therapy with humanized monoclonal antibody to HER-2 receptor and DNA-reactive drugs. Oncogene 17:2235-2249

Prisco A, De Berardinis P (2012) Filamentous bacteriophage fd as an antigen delivery system in vaccination. Int $\mathbf{J}$ Mol Sci 13:5179-5194

Qi H, Egen JG, Huang AY et al (2006) Extrafollicular activation of lymph node B cells by antigen-bearing dendritic cells. Science 312:1672-1676

Raina D, Ahmad R, Joshi MD et al (2009) Direct targeting of the mucin 1 oncoprotein blocks survival and tumorigenicity of human breast carcinoma cells. Cancer Res 69:5133-5141

Raina D, Uchida Y, Kharbanda A et al (2014) Targeting the MUC1$\mathrm{C}$ oncoprotein downregulates HER2 activation and abrogates trastuzumab resistance in breast cancer cells. Oncogene 33:3422-3431

Razazan A, Behravan J, Arab A et al (2017) Conjugated nanoliposome with the HER2/neu-derived peptide GP2 as an effective 
vaccine against breast cancer in mice xenograft model. PLoS One 12:e0185099

Razazan A, Nicastro J, Slavcev R et al (2019) Lambda bacteriophage nanoparticles displaying GP2, a HER2/neu derived peptide, induce prophylactic and therapeutic activities against TUBO tumor model in mice. Sci Rep 9:2221

Rovero S, Amici A, Di Carlo E et al (2000) DNA vaccination against rat her-2/Neu p185 more effectively inhibits carcinogenesis than transplantable carcinomas in transgenic BALB/c mice. J Immunol 165:5133-5142

Sabahi Z, Salek R, Heravi RE et al (2010) Association of gastric cancer incidence with MDR1 gene polymorphism in an ethnic Iranian population. Indian J Cancer 47:317-321

Sadri-Ardalani F, Shabani M, Amiri MM et al (2016) Antibody response to HER2 extracellular domain and subdomains in mouse following DNA immunization. Tumour Biol 37:1217-1227

Salgado R, Denkert C, Campbell C et al (2015) Tumor-infiltrating lymphocytes and associations with pathological complete response and event-free survival in HER2-positive early-stage breast cancer treated with lapatinib and trastuzumab: a secondary analysis of the NeoALTTO trial. JAMA Oncol 1:448-455

Schmid P, Adams S, Rugo HS et al (2018) Atezolizumab and nabpaclitaxel in advanced triple-negative breast cancer. N Engl J Med 379:2108-2121

Scholl SM, Balloul JM, Le Goc G et al (2000) Recombinant vaccinia virus encoding human MUC1 and IL2 as immunotherapy in patients with breast cancer. J Immunother 23:570-580

Schreiber RD, Old LJ, Smyth MJ (2011) Cancer immunoediting: integrating immunity's roles in cancer suppression and promotion. Science 331:1565-1570

Slamon DJ, Leyland-Jones B, Shak S et al (2001) Use of chemotherapy plus a monoclonal antibody against HER2 for metastatic breast cancer that overexpresses HER2. N Engl J Med 344:783-792

Slichenmyer WJ, Fry DW (2001) Anticancer therapy targeting the erbB family of receptor tyrosine kinases. Semin Oncol $28(5$ Suppl):67-79

Solinas C, Gombos A, Latifyan S et al (2017) Targeting immune checkpoints in breast cancer: an update of early results. ESMO Open 2:e000255

Sotiropoulou P, Perez S, Iliopoulou E et al (2003) Cytotoxic T cell precursor frequencies to HER-2 (369-377) in patients with HER-2/ neu-positive epithelial tumours. Br J Cancer 89:1055-1061

Srivatsan S, Patel JM, Bozeman EN et al (2014) Allogeneic tumor cell vaccines: the promise and limitations in clinical trials. Hum Vaccin Immunother 10:52-63

Stewart TJ, Smyth MJ (2009) Chemokine-chemokine receptors in cancer immunotherapy. Future Med 1:109-127

Su M, Huang CX, Dai AP (2016) Immune checkpoint inhibitors: therapeutic tools for breast cancer. Asian Pac J Cancer Prev 17:905-910

Sugie T, Toi M (2017) Antitumor immunity and advances in cancer immunotherapy. Breast Cancer 24:1-2

Swain SM, Baselga J, Kim SB et al (2015) Pertuzumab, trastuzumab, and docetaxel in HER2-positive metastatic breast cancer. N Engl J Med 372:724-734

Takahashi H, Wilson B, Ozturk M et al (1988) In vivo localization of human colon adenocarcinoma by monoclonal antibody binding to a highly expressed cell surface antigen. Cancer Res 48:6573-6579

Tan TJ, Chan JJ, Kamis S et al (2018) What is the role of immunotherapy in breast cancer. Chin J Clin Oncol 7:13
Teulon I, Alvarez N, Behar G et al (2006) 121 POSTER Isolation and characterisation of anti-idiotypic $\mathrm{scFv}$ antibody fragments and llama VHH domains used as a surrogate tumour antigen to elicit an anti-HER-2 humoral response in mice. EJC Suppl 4:40

Todryk SM, Gough MJ, Pockley AG (2003) Facets of heat shock protein 70 show immunotherapeutic potential. Immunology 110:1-9

Tomasicchio M, Semple L, Esmail A et al (2019) An autologous dendritic cell vaccine polarizes a Th-1 response which is tumoricidal to patient-derived breast cancer cells. Cancer Immunol Immunother 68:71-83

Tran T, Diniz MO, Dransart E et al (2016) A therapeutic Her2/neu vaccine targeting dendritic cells preferentially inhibits the growth of low Her2/neu-expressing tumor in HLA-A2 transgenic mice. Clin Cancer Res 22:4133-4144

Vassilaros S, Tsibanis A, Tsikkinhs A et al (2007) 10 years follow up of pilot phase Iii immunotherapy study in early stage breast cancer patients using oxidized mannan-muc1. Breast Cancer Res Treat 106:S31-S31

Viehl CT, Becker-Hapak M, Lewis JS et al (2005) A Tat fusion protein-based tumor vaccine for breast cancer. Ann Surg Oncol $12: 517-525$

Viola A, Contento RL, Molon B (2006) T cells and their partners: the chemokine dating agency. Trends Immunol 27:421-427

Wang W, Li Y, Wang Y et al (2018) Polyactin A is a novel and potent immunological adjuvant for peptide-based cancer vaccine. Int Immunopharmacol 54:95-102

Watson DS, Endsley AN, Huang L (2012) Design considerations for liposomal vaccines: influence of formulation parameters on antibody and cell-mediated immune responses to liposome associated antigens. Vaccine 30:2256-2272

Williams AD, Payne KK, Posey AD et al (2017) Immunotherapy for breast cancer: current and future strategies. Curr Surg Rep $5(12): 31$

Wolchok JD, Hodi FS, Weber JS et al (2013) Development of ipilimumab: a novel immunotherapeutic approach for the treatment of advanced melanoma. Ann NY Acad Sci 1291:1-13

Xie Y, Chen Y, Ahmed K et al (2013) Potent CD4 + T cell epitope P30 enhances HER2/neu-engineered dendritic cell-induced immunity against $\mathrm{Tg} 1-1$ breast cancer in transgenic FVBneuN mice by enhanced CD $4+\mathrm{T}$ cell-stimulated CTL responses. Cancer Gene Ther 20:590-598

Yang B, Jeang J, Yang A et al (2014) DNA vaccine for cancer immunotherapy. Hum Vaccin Immunother 10:3153-3164

Yazdian-Robati R, Ramezani M, Khedri M et al (2017) An aptamer for recognizing the transmembrane protein PDL-1 (programmed death-ligand 1), and its application to fluorometric single cell detection of human ovarian carcinoma cells. Microchim Acta 184:4029-4035

Yoshino I, Goedegebuure PS, Peoples GE et al (1994) HER2/neuderived peptides are shared antigens among human non-small cell lung cancer and ovarian cancer. Cancer Res 54:3387-3390

Zhou X, Liu R, Qin S et al (2016) Current status and future directions of nanoparticulate strategy for cancer immunotherapy. Curr Drug Metab 17:755-762

Publisher's Note Springer Nature remains neutral with regard to jurisdictional claims in published maps and institutional affiliations. 